\title{
ROLE OF INTERDISCIPLINARY COOPERATION IN PROCESS OF DOCUMENTATION OF CULTURAL HERITAGE
}

\author{
Jindřich HODAČํㅜ, Michael RYKL ${ }^{2}$ \\ ${ }^{1}$ Czech Technical University in Prague, Faculty of Civil Engineering \\ ${ }^{2}$ Czech Technical University in Prague, Faculty of Architecture \\ Thákurova 7, Prague 6, Czech Republic \\ hodac@fsv.cvut.cz, rykl@fa.cvut.cz
}

Keywords: metrical documentation, building-historical research, photogrammetry, cooperation, education

\begin{abstract}
This paper is focused on presentation of results of long-term interdisciplinary cooperation in a process of documentation of Cultural Heritage. There are two sides joined in this cooperation. The first side is a "submitter" - in our case it means architect-historian (Mr. Rykl). The second side is a „contractor” - in our case it means surveyorphotogrammetrist (Mr. Hodač and his students). We are cooperating mostly on projects of metrical documentation of Culture Heritage buildings and sites. Our cooperation is realizing mainly in bachelor's/master's projects. Other opportunity for our collaboration is our course [1]. We are offering this course to students of two faculties/specializations (surveyors + architects). Beside the wide range of real results (2D drawings, 3D models, photomaps etc.) we also collected quite a lot of experience with process of collaboration itself. Cooperation and communication of submitter and contactor are playing key roles for successful project. It is possible to generally expect that submitter will give the ,task" and contractor will try to find proper technology to solve it. The process of communication should be permanent because new circumstances and findings are arising all the time. It is very important for all together to find common language across specializations to understand each other. Surveyors are „,slightly pressed" to get more knowledge about historical building constructions. Architects-historians should get basic awareness about various recent technologies for metrical documentation and its ,,pros and cons".
\end{abstract}

\section{INTRODUCTION}

The projects we are cooperating on are mostly practically oriented. Course of our typical project evolved during period of our collaboration into a stable form. This form is showed in Appendix 1. Each side involved has a specific role in the project. What is different from common submitter - contractor relationship is very narrow and intensive cooperation before, during and after the project. Both sides are highly motivated and they are following the same aim. Contractors/students are softly dragged into process of building-historical research (BHR). Finally, they clearly know what they are working on and what the purpose is. This situation helps them to activate their creativity and their ability to manage with emerging questions is gradually growing.

\subsection{Cooperation - main characteristics}

Submitter is defining each task within the project with regard to the specific goal of the BHR. We (submitter+contractor) are then trying to find appropriate way of record to meet the goal. This process of clarifying the form and content is continuous. In some cases it leads to usage of very complex technologies (e.g. laser scanning, optical correlation systems etc.) and in other cases only very simple methods are used (e.g. image rectification). Wide range of technologies is available today. From technological point of view nearly ,all is possible”. Our approach in this technological area is quite pragmatic. It means we are searching for technologies that are as simple and yet fully solve the task. Effectiveness of means used in projects is one of important parameters we are following. Our most common approach is a combination of various documentation methods. Our communication has often a form of dialog. Submitter is making a goal-oriented probe into the subject of research and based on that he is defining clear questions to contractor. Dialog leads us through project systematically. Partial outputs of project help submitter to ,understand deeply" during process of BHR and then to define tasks for next step. From this point of view the whole process is alive, variable, trial-error oriented but following main goal of the project.

Understanding each other is key point of communication. Specializations involved have their own terminology, own language. First essential step is to find the same level of conversation, which is clear for both sides. Crossing of borders of specializations is necessary as well as ability of attentive listening and patient explaining. Only under these 
conditions of mutual interaction we can achieve the state when submitter is able to specify ,,what he really needs" and contractor is able to find and simply explain ,how to do it”. The above-described type of relationship should reduce or even remove some kind of impatience to new technologies on the historian's side and kind of blind fascination to same technologies on the surveyor's side. Cultivation of the ability to have a ,health distance” from own specialization is useful ingredient in this process.

\subsection{Cooperation - types of projects}

Projects we are collaborating on can be divided into four basic types. Each type has its own specifics. Various kinds of activities are usually blending in a project but one of them is always dominant. The main activity is in a direct relation with the main goal of the project. The first type of our projects is „RESEARCH”. It covers projects which are purely focused on research in the area of BHR. Most of them have a form of dialog and documentation results are innovative. The second type is „SUPPORT”. This includes projects that are focused on a creation of metrical documentation as a support of standard BHR process. Results of these projects are common types of metrical documentation. The third type is ,EMERGENCY”. Such projects are focused on emergency documentation of details or complex of buildings and sites. The fourth type of our projects is „PRESENTATION”. The main purpose of these projects is presentation of the BHR results. All these types will be discussed in more detail in the following chapters.

\section{RESEARCH PROJECTS}

This type of projects is mainly focused on verifying of hypotheses about building/site development. Hypotheses are defined by submitter during a process of BHR. Topic of project can be e.g. reconstruction of geometric shape of parts of buildings which were destroyed during ages. This reconstruction is then created on the base of precise metrical documentation of their rests. Various methods are used for documentation in this case and most common output has a form of 3D model. Second type of topics is focused on precise documentation of parts of buildings which exist in original state but their shape and its geometry is not precisely known. Research targeted on geometry of vaults is example of this type of project. Communication submitter-contractor in these projects is the most intensive. The course of projects is continuously modified based on the partial outputs. The main features of this type of projects are summarized in Table 1.

\begin{tabular}{|c|c|c|}
\hline \multirow{3}{*}{ 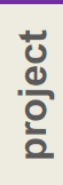 } & goals & verify hypotheses on building development \\
\hline & technologies & combination, whole range, unconventional approaches \\
\hline & results & mostly 3D \\
\hline \multirow{5}{*}{$\begin{array}{l}\text { 드 } \\
\frac{1}{0} \\
\frac{T}{0} \\
\frac{0}{0} \\
\frac{0}{0}\end{array}$} & specifics & intensive dialogue between specializations \\
\hline & & changes in course of project .. step by step \\
\hline & benefits & new findings about development of object \\
\hline & & new findings about technologies \\
\hline & & deeper understanding across specializations \\
\hline
\end{tabular}

Table 1: Research projects - main features

\subsection{Example 1 - geometry of existing vault}

This project was focused on verification of hypothesis about construction of vault of Gothic hall in a small fortress in Central Bohemia [2]. Laser scanning technology was used as a main documentation method. Various types of outputs were created in near cooperation with submitter or directly on his demand. Construction process of this vault was finally clarified by submitter with the help of documentation results. This project was presented in conference of BHR in form of a dialog between submitter and contractor (questions-answers). Various types of results are presented on Figures 1 and 2. 


\subsection{Example 2 - geometry of destroyed vault}

These two projects were focused on verification of hypothesis about geometric shape of vaults which were not preserved. Vault of scullery in a Gothic fortress in Southern Bohemia was topic of the first project and vault of a pulpit of a Romanesque church in Western Bohemia was the second topic. Combination of methods was used in both projects. Stereophotogrammetry and optical correlation system were used as main methods for precise documentation of rests of vaults. Reconstruction of hypothetic shape of vault was created in narrow cooperation and with great help of submitter and enriched our knowledge about historical development of these buildings. Results of projects are shown on Figures 3 and 4.

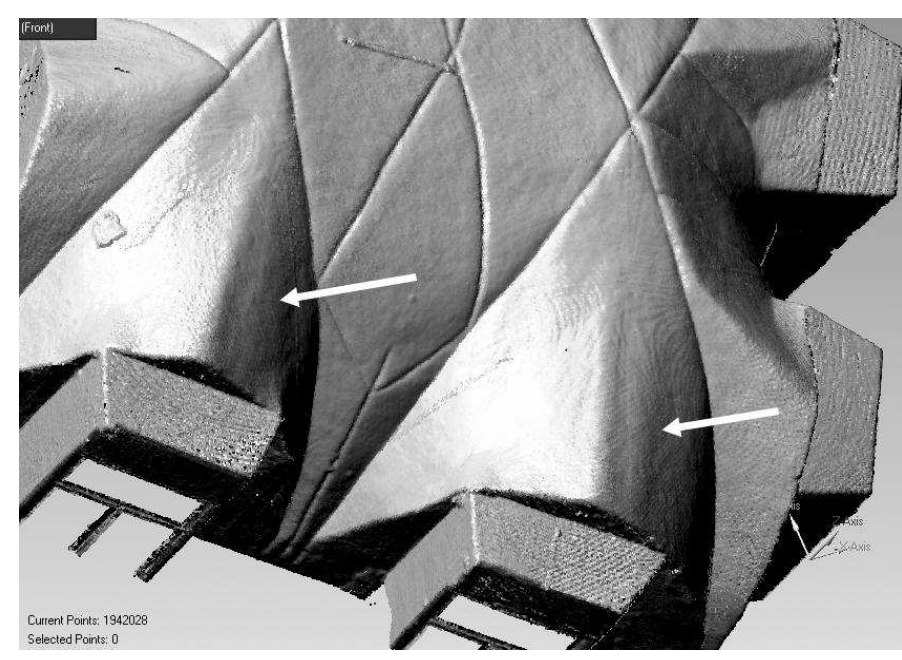

Figure 1: analysis of vault $-3 \mathrm{D}$ model

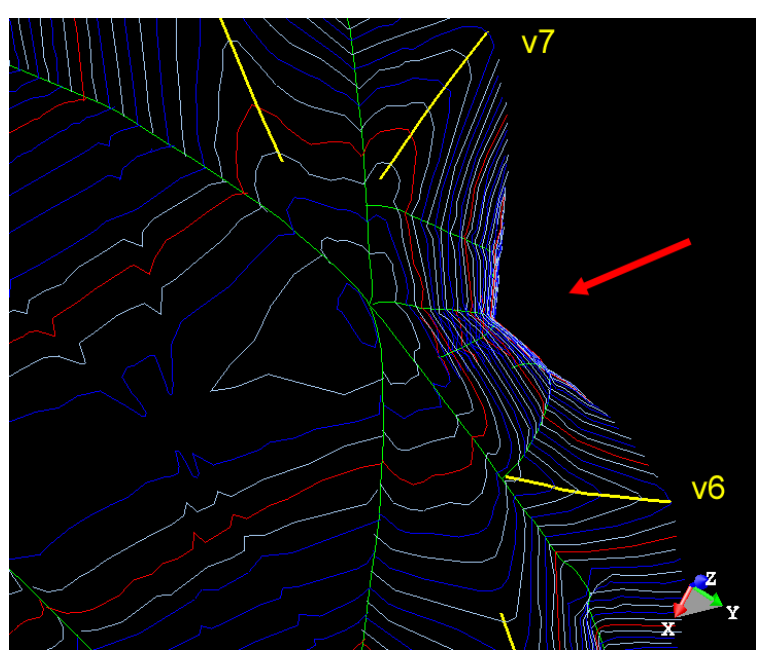

Figure 2: analysis of vault - contour lines

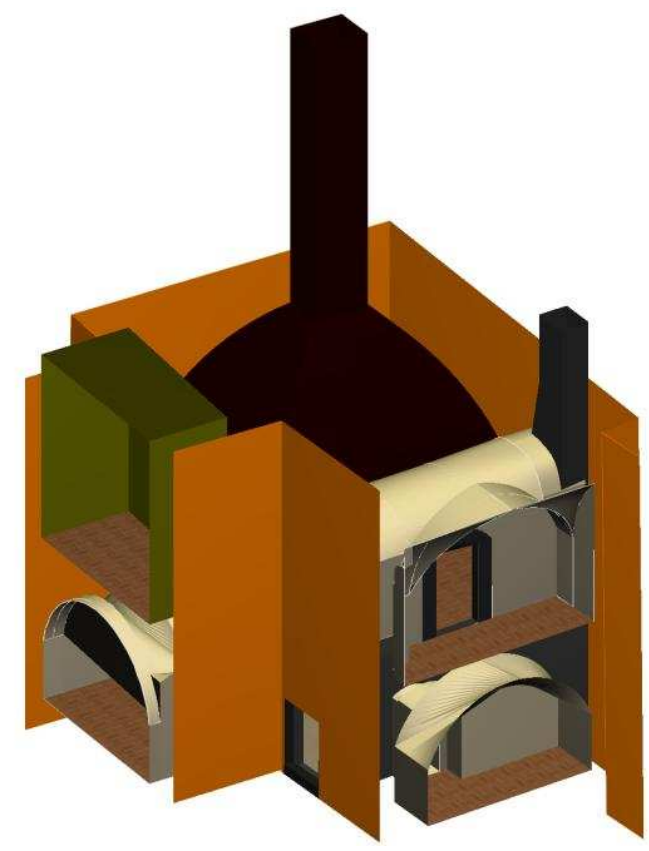

Figure 3: reconstruction of scullery vault

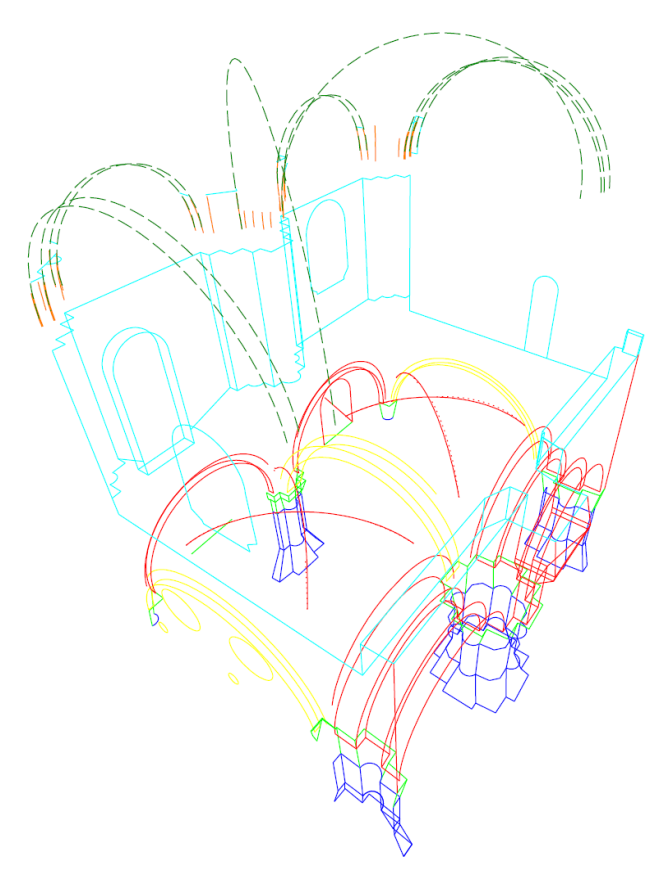

Figure 4: reconstruction of vault of church pulpit 


\section{SUPPORT OF BHR PROJECTS}

This type of projects is mainly focused on creation of a quality-fundament for BHR process. Parameters and forms of outputs are clarified during submitter-contractor discussions. This type of communication can continue throughout the whole course of a project and it is leading to results which are highly customized to the submitter's needs. Results are almost immediately used for BHR done by submitter. Combinations of various methods are used for documentation in this case and the most common output has a form of 2D data (e.g. photomap). Methods used are mostly more simple then in other types of projects. Processing of results is sometimes done partly by contractor with help of submitter, it means, that both sides are slightly pushed to cross rigid borders of their specializations. The main features of this type of projects are summarized in Table 2 .

\begin{tabular}{|c|c|c|}
\hline \multirow{3}{*}{$\begin{array}{l}\overleftarrow{U} \\
\stackrel{\mathbb{d}}{0} \\
\stackrel{0}{2}\end{array}$} & goals & creation of quality base for BHR \\
\hline & technologies & combination, simpler methods preferred \\
\hline & results & mostly 2D \\
\hline \multirow{4}{*}{$\begin{array}{l}\frac{c}{0} \\
\frac{0}{\pi} \\
\frac{\pi}{\pi} \\
\frac{0}{0} \\
\stackrel{0}{0}\end{array}$} & specifics & search for appropriate parameters and forms of output \\
\hline & & crossing boundaries between specializations \\
\hline & benefits & customized high quality documentation \\
\hline & & traditional result with added information \\
\hline
\end{tabular}

Table 2: Support projects - main features

\subsection{Example 1 - photomap and its interpretation}

This project was focused on a creation of photomaps of part of facades of a small fortress in Central Bohemia [3]. Standard workflow of single image photogrammetry was used and photomaps were created. The second step of project was building historical interpretation of the content of photomaps. Intensive submitter-contractor cooperation was necessary during early parts of this period. Quality check done by submitter was the final step. Example of a result is shown on Figure 5.

\subsection{Example 2 - photomap with cross-section}

This project had similar assignment as the project presented above. Building of interest and methods used were also the same. The second step was different. Introjections of cross-section into photomap were demanded by submitter to understand more deeply spatial composition of the selected parts. Key communication submitter-contractor was done during period of fieldwork when parameters of cross-section were clarified in situ. Standard surveying methods were used for cross-section documentation. Example of a result is shown on Figure 6.

\section{EMERGENCY DOCUMENTATION PROJECTS}

This type of projects is mainly focused on emergency documentation of buildings/sites and its parts at risk. Time, work safety and technical conditions on site play key roles in these projects. Demand for documentation is formulated by submitter. It is really necessary to discuss and brightly identify priorities of project and parameters of results. Technologies for quick collection of maximum data are commonly used because of circumstances of such projects. Laser scanning and optical correlation systems are widely used and results are in a form of 3D model. Conditions during data collection process are often difficult (not much space, not much light, time press etc.). It has some influence on data quality but mostly it is not possible to wait for better conditions in field (e.g. archeological prospecting with excavator above head). Close submitter-contractor cooperation is necessary in a process of search for effective technology of documentation. High end technologies as e.g. laser scanning are not available and also not convenient at every time for various reasons (budget etc.). The main features of this type of projects are summarized in Table 3 . 


\begin{tabular}{|c|c|c|}
\hline \multirow{3}{*}{$\begin{array}{l}\text { ปั } \\
\frac{d}{0} \\
\frac{0}{2}\end{array}$} & goals & emergency documentation of sites at risk \\
\hline & technologies & combination, whole range, quick data collection \\
\hline & results & mostly 3D \\
\hline \multirow{4}{*}{$\begin{array}{l}\frac{5}{0} \\
\frac{0}{10} \\
\frac{\pi}{0} \\
\frac{0}{0} \\
\frac{0}{0} \\
0\end{array}$} & specifics & clarification of priorities for documentation \\
\hline & & time, safety and technical conditions \\
\hline & benefits & data recorded for future \\
\hline & & search for effective technologies of documentation \\
\hline
\end{tabular}

Table 3: Emergency projects - main features

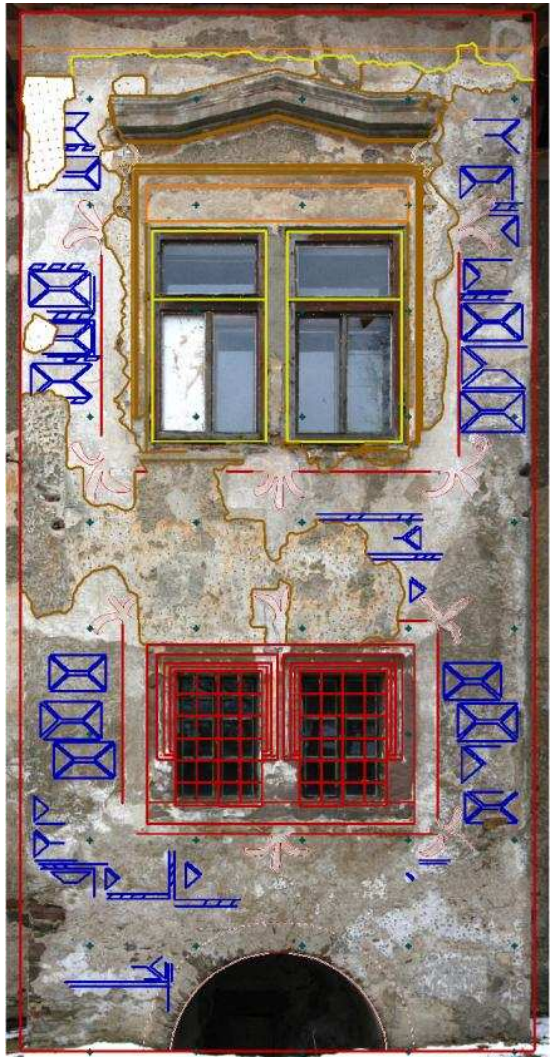

Figure 5: interpretation of photomap

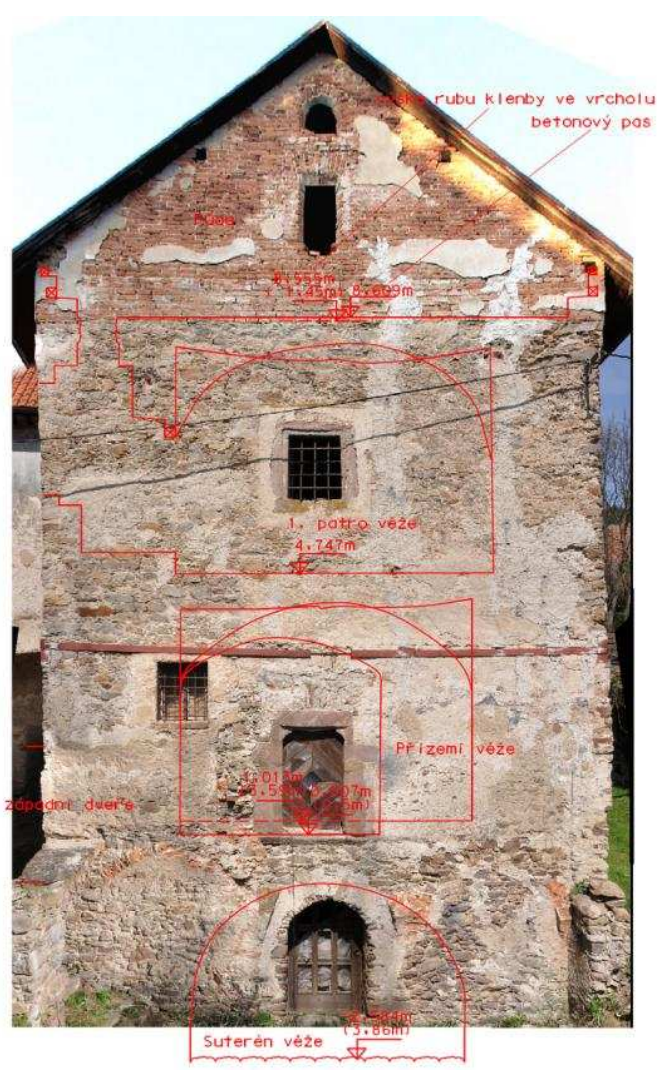

Figure 6: photomap with cross-section

\subsection{Example 1 - stucco decoration of vault}

This project was focused on emergency documentation of the most valuable parts of stucco decoration (putti) of a baroque vault in a castle near Prague. Optical correlation system was used as a main documentation technology. Very detailed 3D models of putties were created and also complex model (not so detailed) of the whole vault was another result. Slow destruction of the vault and its decorations were discovered during the course of the project. Partial results of processing were discussed and high emphasis on punctuality of documentation from side of submitter opened necessity of next phases of fieldwork. This process of continuous regimentation led to very high quality outputs. Example of a result is shown on Figure 7.

\subsection{Example 2 - archeological site}

This project was focused on emergency documentation of archeological site in the centre of Prague [4]. Laser scanner technology was not available, just optical correlation technology was used similarly as in the first project. Huge amount 
of image data was collected and they are still processed step by step. Conditions during fieldwork were not ideal (time press, light problems) but detailed 3D model of part of the site was already created in a high quality. Close cooperation, help and patience was necessary mainly during the onsite work (many people in small space etc.). Documented ruins were destroyed few days after last fieldwork. Collected data are from this point of view very valuable source of information for the future. Example of a partial result is shown on Figure 8.

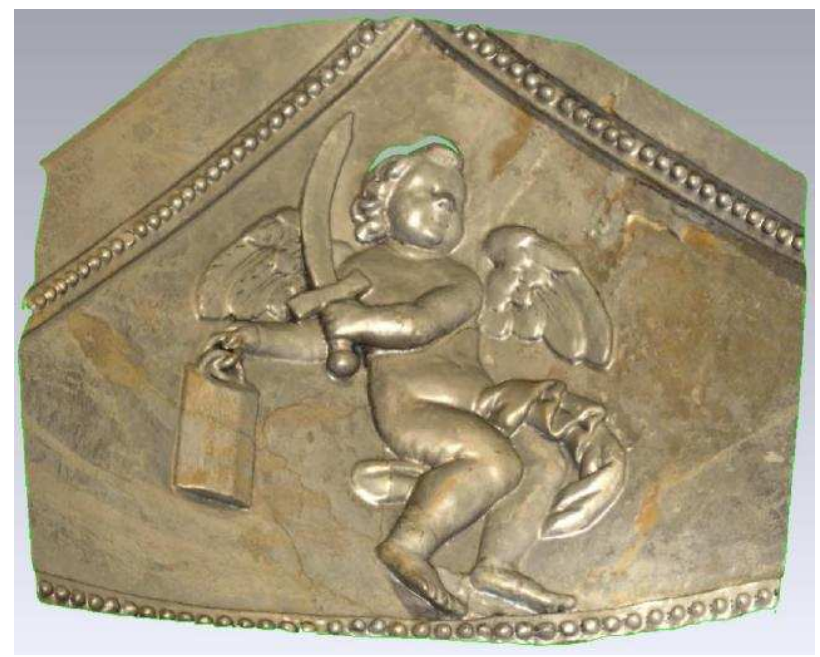

Figure 7: textured 3D model of putti

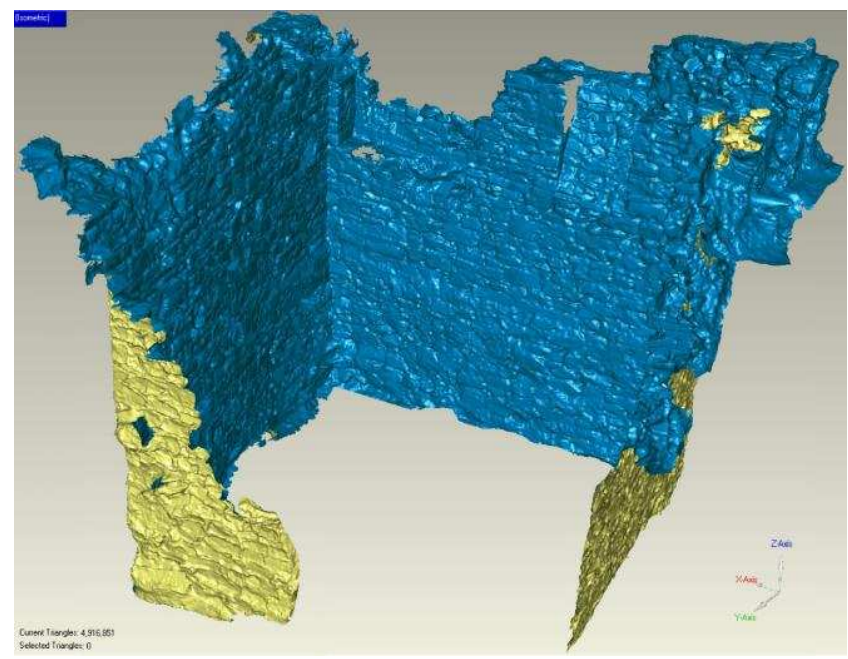

Figure 8: 3D model of part of Matthew tower

\section{PRESENTATION PROJECTS}

This type of projects is mainly focused on illustrative presentation of research outputs. Standard graphic form of BHR outputs is two dimensional (drawings, schemes etc.). Visualization (3D model) of findings gives better idea about spatial relationship of different parts of building/sites. Submitter defines the main task of visualization. Subsequent discussion with contractor leads to proposal of technology, parameters and forms of results. Existing data sources are mostly combined with supplemental measurement (different simple methods) in situ. Submitter is fully involved in the process of creation of final results. These results in some cases reveal the necessity of partial BHP improvement. The main features of this type of projects are summarized in Table 4.

\begin{tabular}{|c|c|c|}
\hline \multirow{3}{*}{$\begin{array}{l}\text { 어 } \\
\frac{0}{0} \\
\text { 을 }\end{array}$} & goals & presentation of collected research outputs \\
\hline & technologies & combination, use of existing data \\
\hline & results & mostly 3D, visualization, animation \\
\hline \multirow{4}{*}{ 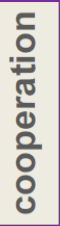 } & specifics & working with various data sources \\
\hline & & working with results of research - explanation/understanding \\
\hline & benefits & search for optimal methods of presentation \\
\hline & & suggestions for improving of research \\
\hline
\end{tabular}

Table 4: Presentation projects - main features

\subsection{Example 1 - reconstruction of historical appearance of a fortress}

This project presented results of BHR of a part of a small Gothic fortress in Southern Bohemia [5]. 3D model was created using existing 2D drawings (earlier metrical documentation), results of BHR and simple measurement in building. Measurement by tape was performed in order to improve the above mentioned 2D drawings. Detailed photodocumentation was also taken. 3D model displays a hypothetic state of the building during researched historical period. 
Results of project were presented together with other results of BHR on a specialized seminar. Example of a result is shown on Figure 9.

\subsection{Example 2 - development of ramparts}

This project presented results of BHR of ramparts of a Gothic fortress in Central Bohemia [5]. Intersection photogrammetry was used as a method of documentation. The output was a 3D model of actual state of the area of interest. This model was combined with 2D drawings (BHR outputs). Projection of these drawings to the 3D model was done in a narrow cooperation between submitter and contractor. Final 3D model allows better understanding of building development. Created model became one of important sources for reconstruction of appearance of the fortress in various historical eras. These reconstructions were done by submitter consequently. Example of a result is shown on Figure 10 .
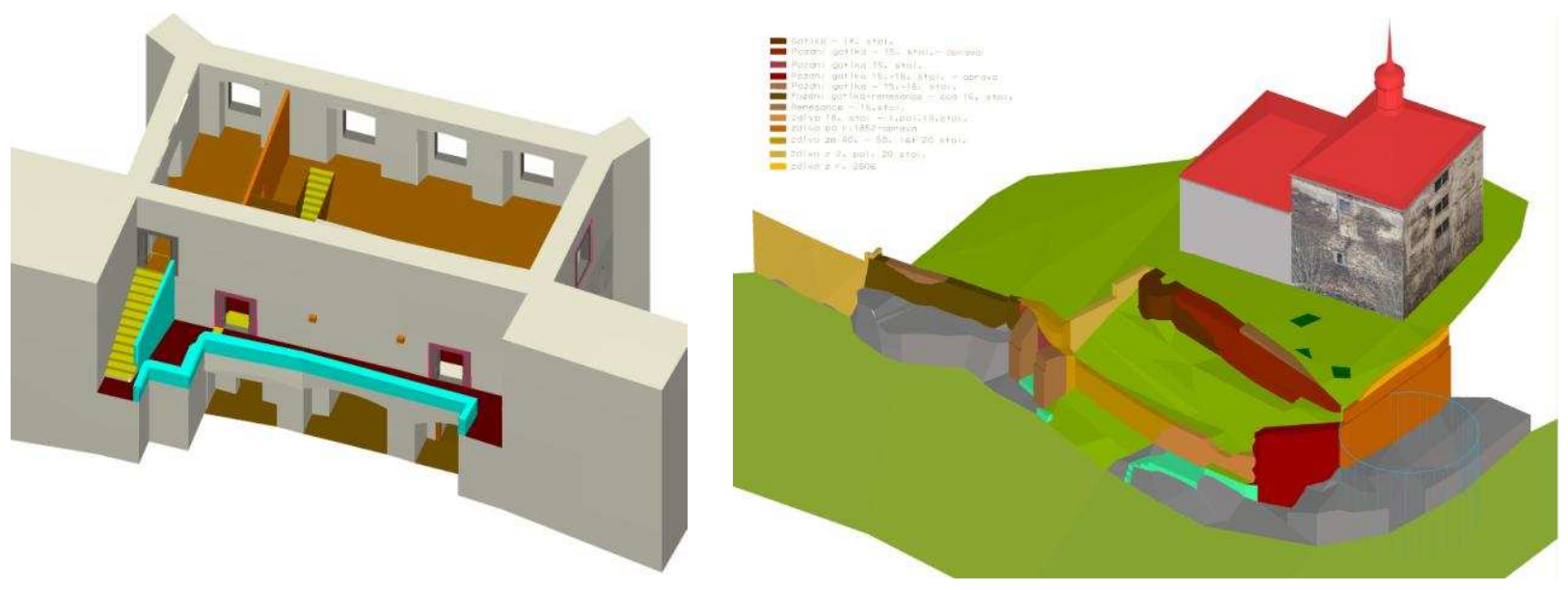

Figure 9: reconstruction of a part of a fortress

Figure 10: historical development of ramparts

\section{CONCLUSION}

We can say that described type of cooperation is leading to results of a very good-quality. Yes, it is true, that it is quite time demanding for all, but specialists from both sides are enriched and finally they are very satisfied with the project and its results. We cannot expect that in a real life the course of the projects will always run as ideally as we are practicing. We are trying to show to our students the way how to do it, what is important in the process and last but not least how to make interdisciplinary collaboration successful.

\section{REFERENCES}

[1] Hodac, J., Rykl, M.: Metrical documentation of historical buildings - joined course of Faculty of Civil Engineering and Faculty of Architecture CTU in Prague, DESTA 2008, Nečtiny, March 2008,

lfgm.fsv.cvut.cz/ hodac/dokumenty/Hodac_Nectiny2008.pdf, 2011-05-29

[2] Rykl, M., Sunkevic, M., Hodac, J.: Gothic vault of hall of fortress in Popovice, Proceedings of 5. Conference of BHR, Znojmo, June 2006, 365-380

[3] Hodac, J.: Simple photogrammetry in applications of Culture Heritage documentation, Proceedings of Workshop of Photogrammetry and Remote Sensing, Telč, November 2009, 51-56.

[4] Frydecky, L., Hodac, J.: Creation of 3D model of archeological site, Proceedings of 10. Conference - Computer support in archeology, Dalešice, May 2011, in print.

[5] Rykl, M.: Composition of residential part of medieval fortress in Bohemia, dissertation thesis, Prague, CTU Faculty of Architecture, 2010.

[6] Pavelka, K., Řezníček, J.: New Low-cost 3D Scanning Techniques for Cultural Heritage Documentation. In Proceedings of the ISPRS XXI Congress [CD-ROM]. Beijing: ISPRS, 2008, vol. 8, p. 222-225. ISSN 1682-1750. [7] Pavelka, K.,̌̌ezníček, J. - Hanzalová, K. - Prunarová, L.: Non Expensive 3D Documentation and Modelling of Historical Objects and Archaeological Artefacts by Using Close Range Photogrammetry. Proceedings of Workshop on Documentation and Conservation of Stone deterioration in Heritage Places 2010 [CD-ROM]. Amman: CulTech for Archeology and Conservation, 2010 


\section{APPENDIX}

Appendix 1: Course of typical project

\begin{tabular}{|c|c|c|c|}
\hline activities during project & $\mathbf{S}$ & C & ST \\
\hline \multicolumn{4}{|l|}{ defined goal of project $=$ purpose } \\
\hline \multicolumn{4}{|l|}{ cooperation } \\
\hline \multicolumn{4}{|l|}{ introductory meeting } \\
\hline - study of basic groundwork/documentation & & & AS \\
\hline - first draft of type of results & & & AS \\
\hline - first draft of convenient technology & & & AS \\
\hline \multicolumn{4}{|l|}{ - agreement on time frame of project } \\
\hline \multicolumn{4}{|l|}{ meantime } \\
\hline - obtaining additional documentation & & SU & \\
\hline - study of documentation & & SU & \\
\hline - study of previous projects of simillar type (technology) & & SU & \\
\hline \multicolumn{4}{|l|}{ fieldwork } \\
\hline - specification of task in situ & & & AS \\
\hline - specification of technology in situ & & & AS \\
\hline \multicolumn{4}{|l|}{ - data collecting + continuous consultation with submitter } \\
\hline \multicolumn{4}{|l|}{ processing } \\
\hline - preprocessing of data & & SU & \\
\hline \multicolumn{4}{|l|}{ - first results - analysis and discussion } \\
\hline \multicolumn{4}{|l|}{ - refinement of technology of processing and form of results } \\
\hline \multicolumn{4}{|l|}{$>$ interactive process .. next meetings } \\
\hline \multicolumn{4}{|l|}{ - final results - discussion } \\
\hline \multicolumn{4}{|l|}{ conclusion - reflexion } \\
\hline \multicolumn{4}{|l|}{ - benefits to submitter } \\
\hline \multicolumn{4}{|l|}{ - benefits to contractor } \\
\hline \multicolumn{4}{|l|}{ - new knowledge of technologies used } \\
\hline - publication and use of outputs & & & \\
\hline
\end{tabular}

Activities of all parties involved are displayed on right side of table. 